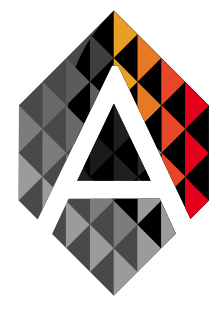

ADCAIJ: Advances in Distributed Computing and Artificial Intelligence Journal Regular Issue, Vol. 8 N. 2 (2019), 51-60

eISSN: $2255-2863$

DOI: http://dx.doi.org/10.14201/ADCAIJ2019825160

\title{
Education System re-engineering with AI (artificial intelligence) for Quality Improvements with proposed model
}

\author{
Muhammd Muzammul ${ }^{\mathrm{a}}$ \\ a Department of Software Engineering, Govt. College University, Allama Iqbal road 38000, Faisalabad, \\ Pakistan \\ m.muzammul275@gcuf.edu.pk
}

KEYWORD

Reengineering; Artificial intelligence (AI); Multi-face Recognition; Facial Expression (FE); Decision making; Quality assurance; Brain simulation; Quality Education; AI; Expert (ES)

\section{ABSTRACT}

Re-engineering (RE) of existing educational institutions (EI) with adoption of latest technology trends (LTT) in form of artificial intelligence (AI) can be great effective in term of quality systems. Increase in student's strength in class and terrorist attacks on EI urged us to introduce such approach that can assure education quality. Class monitoring with heavy strength always remain major issue for teacher during lecture delivery. In this paper, we implemented reengineering using artificial intelligence based two theories of 1) Multi-face recognition (MFR) system 2) Facial expression recognition (FER) system. Both of these theories supported by intelligent techniques as principal component analysis (PCA), discrete wavelet transform (DWT) and k-nearest neighbor $(K N N)$. After implementation of these intelligent techniques student's attentiveness will increase. Our developed system can detect expressions like happiness, repulsion, fear, anger, and confusion. Student's attentiveness score will be displayed on screen. Teacher can interpret on the basis of attentiveness \%age. System decision making can be helpful for class continuity or short break. This system is also an application of an expert system (ES) and knowledge base system (KBS) for educational quality assurance. A similar monitoring system was imposed in china with Hikvision Digital Technology. Predations results proved monitoring can be best way for education quality.

\section{Introduction}

Re-engineering deals with the study of existing systems or software add by including or excluding feature in the existing system with goals of a quality product new system developed with a user's demands of quality requirements. As the quality of system deals with effectiveness, reliability, supportability, reusability, and robustness.AI (artificial intelligence) is a field of science and technologies in which day by day new advancements and intelligence expert systems are developing. Human wants to develop intelligent systems that can work as a human. Systems should be capable to work as human thinks and inter-operate output.

Education is the basic need of every society for existence in this developing age. Before research, it was a big problem in universities, colleges, schools to monitor student activities and behaviors during class. Teachers could not deliver a lecture in the peaceful environment due to in serious behaviors of students. Class's strength

Muhammd Muzammul, M. Awais and M. Yahya Saeed Education System re-engineering with Al (artificial intelligence) for Quality Improvements with proposed model
ADCAIJ: Advances in Distributed Computing and Artificial Intelligence Journal Regular Issue, Vol. 8 N. 2 (2019), 51-60 elSSN: 2255-2863 - http://adcaij.usal.es Ediciones Universidad de Salamanca - CC BY NC DC 
increases day by day and due to lack of professionalism, we manage huge classes in big halls. Problem was that students remain whispering during class time or keep talking with each other. In other words, they were not serious with study and there was a big problem for education quality. Due to lack of communication and less intention toward lecture students were away from the actual seed of knowledge.

By analyzing all the situation there was a need to re-engineer the existing education system with the advances in technologies. We proposed a system where we tried to solve the problem. In the classroom, we implemented an intelligent system which works with the help of two approaches. Firstly, Multi-face recognition technology [1], that used by many fields of sciences, in computer science this approach can use for multiple as face-recognition attendance system, recognizing people from the database as I register it or not. This technology also works as government level, if they implement in cities cameras at several places and recognize from NIC it can increase security system and this technology also working in Mechanical, Robotic, criminalistics, etc. Anyhow, here we are recognizing classroom EmguCV [2] crossplatform example given in. net. This library allows capture and process real image by capturing devices in real time. The main working environment of this approach is to implement a face detector and recognize in real time when multiple students present in a classroom using Principal Component Analysis (PCA) [3] with Eigen face with implementation in multiple fields. The second approach is human facial expression recognition (HFER) [4] approach work based on recognized images. After multi-face recognition work, multiple pictures captured from the classroom and time stored in the database. From database HFER get input images and implement several processes from conversion tools RGB to gray-scale and GS to binary and process remain in working and by several measuring and cutting techniques parts of image eye, lips separated and then with saved comparisons in already developed a database, images are compared and interpret the results either the student was worry, fresh, attentive, sad or whispering to others. A graph gets extracted from the facial expressions of students with mainly two focused attributes \%age [5] of attentive and annoying members on separated screen as named student behavior judgmental report. Students try to be attentive if they repelled from the class they can get lost in form of shortage attendance or sessional marks. On the other hand, the teacher also tries to communicate in a well-organized manner to get interested in students. Overall results told that education system improvement can produce real scholars and scientists.

This research is related to an expert or we can say it as the application of artificial intelligence. We gathered report from more than 100 universities nationally from Pakistan and internationally from different developed countries as China, England London and many universities like University of Faisalabad, Pakistan, University of Sargodha Faisalabad, Pakistan and Government College University, Faisalabad, Pakistan. During surveys and online interviews several reports and views collected before and after discussion and proposed analysis report of views of several professors about. Another the cameras that are performed in classrooms for students behaviors judgments in China, we also tried to focus on our research. The whole system is also implemented in Fatima Jinnah postgraduate, college Naya Lahore (FJPGC), Pakistan and got more than $90 \%$ positive results. After one month report, we interpret that student's class atmosphere got better and their combination gaps and lesion weaknesses got clear as they were monitored.

\subsection{System Re-engineering overview}

When an existing system or software don't fulfill the requirements, we apply re-engineering techniques on it and develop a new system with more advanced capabilities. Here we want to implement re-engineering on the existing system and proposed new education system with the help of the latest technologies. Problem of student interaction with teacher got eradicated.

Muhammd Muzammul, M. Awais and M. Yahya Saeed Education System re-engineering with Al (artificial intelligence) for Quality Improvements with proposed model
ADCAIJ: Advances in Distributed Computing and Artificial Intelligence Journal Regular Issue, Vol. 8 N. 2 (2019), 51-60 eISSN: 2255-2863 - http://adcaij.usal.es Ediciones Universidad de Salamanca - CC BY NC DC 


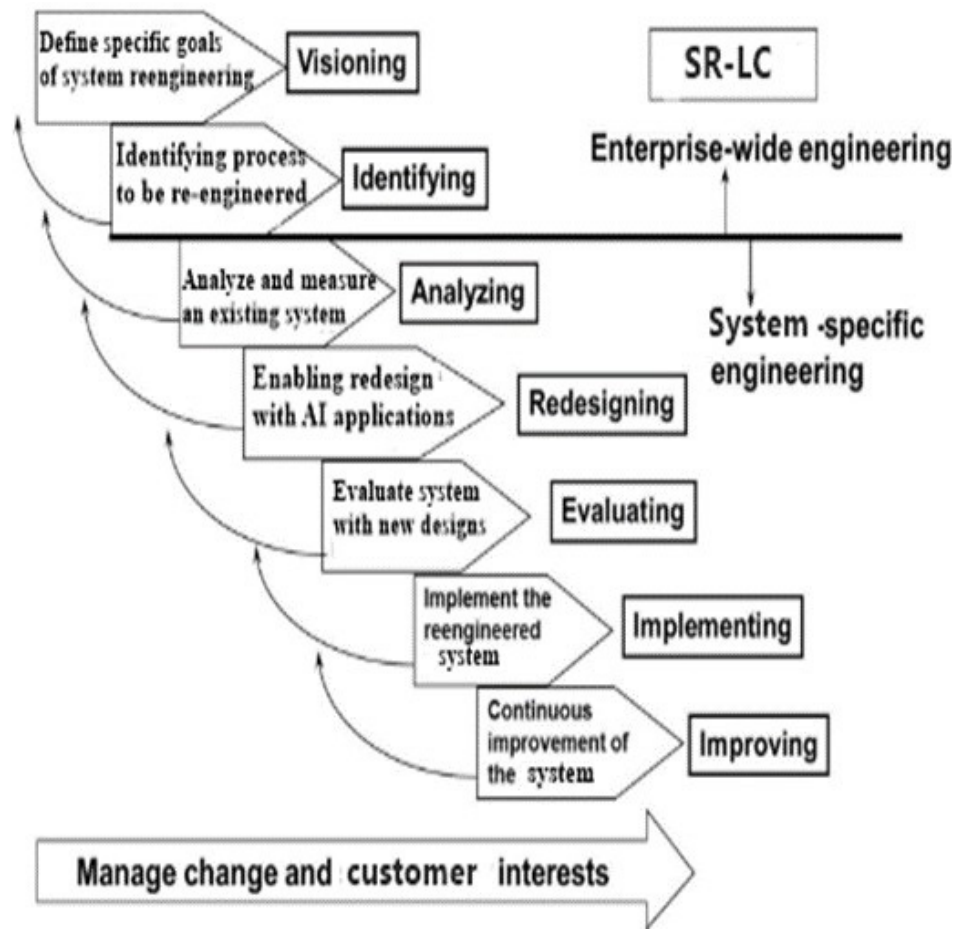

Figure 1: System Re-engineering Life Cycle (SR-LC).

Visioning: Before developing any system we think about system requirements and user's requirements for quality assurance.it should define all the changing and clear.

Identifying: We identify the needs of system re-engineering. What is the reason and why we need the new system? We tried to test the aspects that lead to re-engineering needs. All type of quality lacks in the existing system become plus points in new system identified before system development.

Analyzing: We analyze already implemented systems and check the environment, tools, and technologies about an existing system. We follow up the process of requirements analysis and test the possibility and impossibility of features in the way of new system development.

Redesigning: We check existing system designed after analyzing the lacks and needs we design the whole system and try to test the costs, time needs, and each of every point.

Evaluation: We test new re-engineered system according to user requirements. We test system with the real-time requirements and demand for user mentality. If user want any amendments, we bring changes in system accordance user's priority.

Implementation: After evaluation system accordance user demand we implement a new system with new quality features

Improving: Within passing day, latest technologies invented several improvement tools. Technologies also change, as the command-line work with changed to GUI. Java to Android and generations and versions of systems and software bringing a change in user's mentality. So, we don't stop our improvement. Within user demand, we bring changes in a developed system about tools and technologies.

\section{B. SR-LC mapped on-FJPGC}

As we are going to re-engineer education system implementation in Pakistan schools. We will map system re-engineering life cycle (SR-LC) of our Fatima Jinnah postgraduate college Naya Lahore (FJPGC). First, we set our mind after studying educational institutes, there is a need to bring a great change to the education system 
with advanced applications, tools, and technologies. We identified the issues common in most institutes. There was no proper attendance system and students behaviors judgmental tool in colleges and universities. That was the main reason $70 \%$ of students after graduation doesn't get proper jobs, because they serve their time with improper education atmosphere.

We identified two major reasons as teachers and students attendance system problems and un-judged students behaviors during lectures. For analysis, we visited different developed countries as studied their education systems as in China we founded Hikvision Digital Technology [8], where student's behaviors were judged during class time by facial expressions. In our FJPGC we implemented a similar system. Several lacks in existing system design and tested parameters for new system design. Technology brings a change in the infrastructure of an educational institute FJPGC with two new AI applications. The new system worked with Multi-Face recognizer technology (MFRT) [6] and the Facial expression recognition system (FERS) [7]. I performed a test of our system on different institutes and our team members. After testing, it has resulted that the new system gave over 90\% accurate results. It implements this system in Fatima Jinnah Education Complex (FJPGC) and it was the whole process of the study mapped with new features in the existing education system.

\section{Complete Methodology Implementation (Proposed Model)}

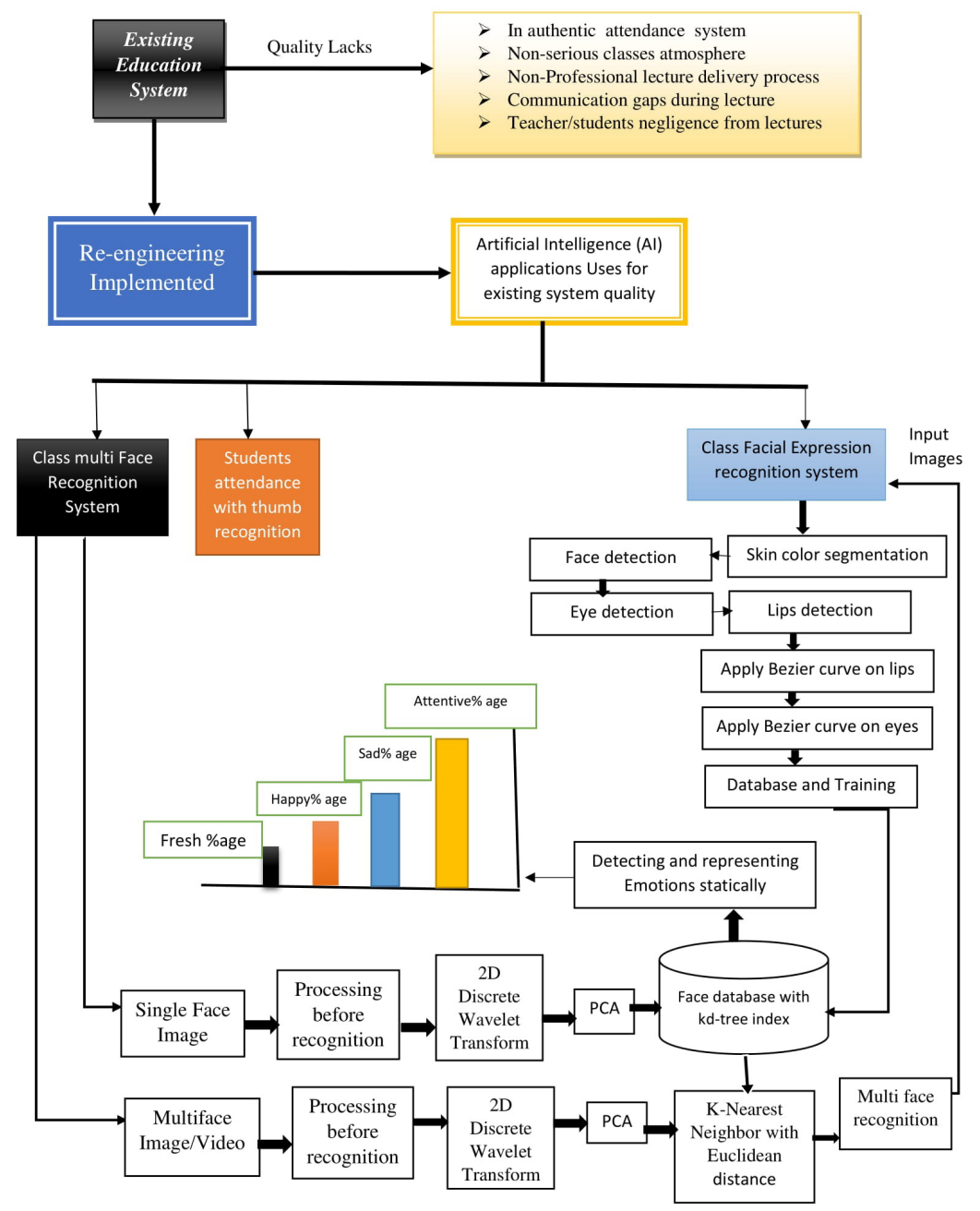

Figure 2: Education system re-engineering with Al applications.

Muhammd Muzammul, M. Awais and M.Yahya Saeed Education System re-engineering with Al (artificial intelligence) for Quality Improvements with proposed model
ADCAIJ: Advances in Distributed Computing and Artificial Intelligence Journal Regular Issue, Vol. 8 N. 2 (2019), 51-60 eISSN: 2255-2863 - http://adcaij.usal.es Ediciones Universidad de Salamanca - CC BY NC DC 


\section{AI (Artificial Intelligence) Role in Society and Education}

Artificial intelligence (AI) inspiring every field of life as online shopping, ATM machines, TV application, automatic remote controls viewing its work in everywhere [9]. It is the hottest topic of study and computational devices made by a human. Education adopted applications of AI. However, according to some people point of view, it will take education toward a student's impairment, where's imagine AI revolutionized and improved education.

So, question is that, what is AI impact on the education system? Will it helpful for students? What can it teach or revolutionize to make students absolute? Artificial intelligence does not minimize classroom atmosphere even if the enhanced quality of education [10]. From last few decades, the education and learning process faces a lot of problems, in quality, in language processing, in-class atmosphere control, students/teachers attendance system, and lecture planning activities.AI, addressed many fields including machine learning, language processing, reasoning, planning, cognitive modeling with the help of AI applications[11]. It is right to say that both Artificial Intelligence and education come into existence for each other. If we imagine, education is a source of mind development and intervening knowledge pool, while AI provides tools and software for the development of more accurate and picture about working of everything. In this research, we introduced AI applications in our Fatima postgraduate college (FPGC) as class face recognizer as attendance system and with a captured face as the input of Facial expression recognition system. It aims quality education and advanced capabilities of human interest.

\subsection{MULTI-Face Recognition System Role in Research}

As we implemented this software in FPGC and interpreted the results based on two main approaches, one is a multi-face recognition software for the student's attendance. There was a huge problem in managing whole class attendance because there were many students in classes, it was time taking an unofficial to manage the whole class by roll calls. Sometimes students cheat and call on other student roll numbers. Teacher waste his time for roll calling as it was a need of each lecture. We introduced this software in FJPGC and teacher start software, after 20 mints startup of lecture and in a few seconds camera recognize a whole class at once. On a single click, it captures class faces and saves in a database for further processing. The whole process followed by the steps explained below.

\section{A. Multi-face/single face image}

They use (Zavio F320) IP camera for capturing an image from the video [12]. Images of a student previously registered in the database with a unique ID. In FJPGC I performed this test on 10 classes including girls and boys campus. There were near 40 students in each class. It saved total 400 faces in DB. Face captured from video using IP camera face by face up to 60 frames. I used different videos with 30dpi and 1080x720 resolution and 3 mints normal duration. Software installed on the class computer and teacher mark attendance after 20 mints startup of class.

\section{B. Processing before recognition (Pre-processing)}

Following the work involved in this stage: Based on each video frame. I detected faces based on Haarlike features [13] by using Viola-jones method that can detect multiple faces at once. They converted from RGB to gray-scale converted and after this resized into a normalized form by using histogram process equalization.

\section{C.2D Discrete Wavelet Transform}

That process used as face database. By reprocessing, 130x130 image size got after resizing into 128x128 that decomposed into $64 \times 64$ pixels on the walvet level first. On the second level it converted into $32 \times 32$ pixel face image and on the third level, it converted into 16x16 pixels. I aimed all experiment to get correct results to recognize many faces. After these images were ready for PCA.

Muhammd Muzammul, M. Awais and M. Yahya Saeed Education System re-engineering with Al (artificial intelligence) for Quality Improvements with proposed model
ADCAIJ: Advances in Distributed Computing and Artificial Intelligence Journal Regular Issue, Vol. 8 N. 2 (2019), 51-60 elSSN: 2255-2863 - http://adcaij.usal.es Ediciones Universidad de Salamanca - CC BY NC DC 


\section{Principle part Analysis (PCA)}

After got wished and compressed image that performed for feature extraction. For recognition, already trained images were present in the database. Multiplication applied by eigenvector for extraction of the image, the reason as to get the vector of training image features. PCA used to compare the original image with a database trained image at the stage of classification [14].

\section{E. kNearest Neighbor (KNN) with Euclidean Distance}

This approach calculates the similarity distance between the two images. They captured images from class and database trained images. It shows all working activity work by Euclidean Distance in the equation...

$$
d(x, y)=\sqrt{\sum_{i=1}^{n}\left(x_{i}-y_{i}\right)^{2}}
$$

\section{Face recognition and input to FERS[15]}

In this study, for the trailing process, I got static and video images from the classroom with the help of a digital camera and IP camera. I collected nearer about 9,000 faces data from 1500 different people. They captured each student's face from six different angles. Test reason was to test the result of an implemented system in FJPGC. Captured and recognized images saved in the database and worked as input for our next application as Facial expression recognition. Above multi-face recognition based attendance bring a change in regularity of students. Every student was beware of the maintain of $90 \%$ attendance. Our system provided a lot of quality in the education system of Fatima Jinnah education complex Naya Lahore, Pakistan.

\subsection{Facial Expression Recognition System Implementation}

After getting recognized faces we store all images in the database. These images work as input for the next system (FERS). The aim of this system is to extract all class facial expressions. Facial expressions tell about physiological, mental attentively. After multi-face recognition, the process, the facial expression recognition system starts its working. It extracts features from captures images and draws a graph about the $\%$ age of attentive and inattentive students. It calculates the expressions as happy, sad, and attentive, disagree, and agree, or whispering, etc. The process passes from following stages.

\section{A. Division of skin color}

We select an image from the database and we contrast the image before fulfilling skin color division. After this, we find out the largest connected region. If the largest connected region fulfills the need then it opens a new form. If the largest connected region provides $50 \%$ accurate ratio and height and width is $1 / 2$ then it can be a face.

\section{B. Detection of faces}

It this phase, we convert an image from binary to Red and green and blue. We calculate the average value of RGB for each image. If the value is bellow than 110, we replace the pixel with a black pixel otherwise it got replaced with a white pixel. This method gives us a binary image from RGB. Then, we cut face from start point of the head with the multiplication 1.5 of its width. Then we apply the on eyes, nose, and lips. It will cut images according to binary.

\section{A. Detection of eyes:}

By performing a different, we cut eyes from middle point of the nose to left and right position

\section{B. Detection of lips:}

We consider lip box and check the image should fit in the box. We put box size $1 / 4$ position of left eye box and $3 / 4$ position of right eye box.

Muhammd Muzammul, M. Awais and M. Yahya Saeed Education System re-engineering with Al (artificial intelligence) for Quality Improvements with proposed model
ADCAIJ: Advances in Distributed Computing and Artificial Intelligence Journal Regular Issue, Vol. 8 N. 2 (2019), 51-60 eISSN: 2255-2863 - http://adcaij.usal.es Ediciones Universidad de Salamanca - CC BY NC DC 


\section{Bezier curve implementation on Lips:}

Where we find skin image part we convert it into white pixel and remaining part into the black pixel. We also use the histogram to find the distance between lover and upper RGB values.

\section{Bezier curve implementation on eyes:}

First we remove eyebrow from eyes. Only eyes present in eye box, on skin color we convert into white pixels and remaining into black pixels.

\section{E. Training database:}

In our database, there present two tables. One table with name Person is for storing the name of people and their index of 4 kinds of emotions we store in Position table. With the of 6 control point from lips and eyes and Bezier curve with the comparison of height and width the program got an understanding of emotions.

\section{F. Emotion got detected:}

For emotion detection of students captured images, we applied the bezier curve on lips, left eye, and right eye. Then we converted it into the width of the Bezier curve to 100 but height according to its width. If the emotions calculated by the whole process work with the database values. Then we test the emotions of each candidate present in class. After calculations of similar emotions as we stored values already with 6 different comparisons in the database, it draws a graph in front of teacher LED. A graphical representation tells the teacher, how many students are attentive, happy, sad, disappointed or in any other situation. Accordance he manages the whole class and all student try to remain attentive as they consider that monitoring system judging their every activity. After one month evaluation of this system on Fatima Jinnah postgraduate college, we got results with a $90 \%$ accuracy rate. This system changed the whole atmosphere of classes. The student was attentive, and I recorded control of a whole class in camera. These facial expressions result left a good impact on their behaviors and bring a change in an education environment.

\section{G. Software representation}

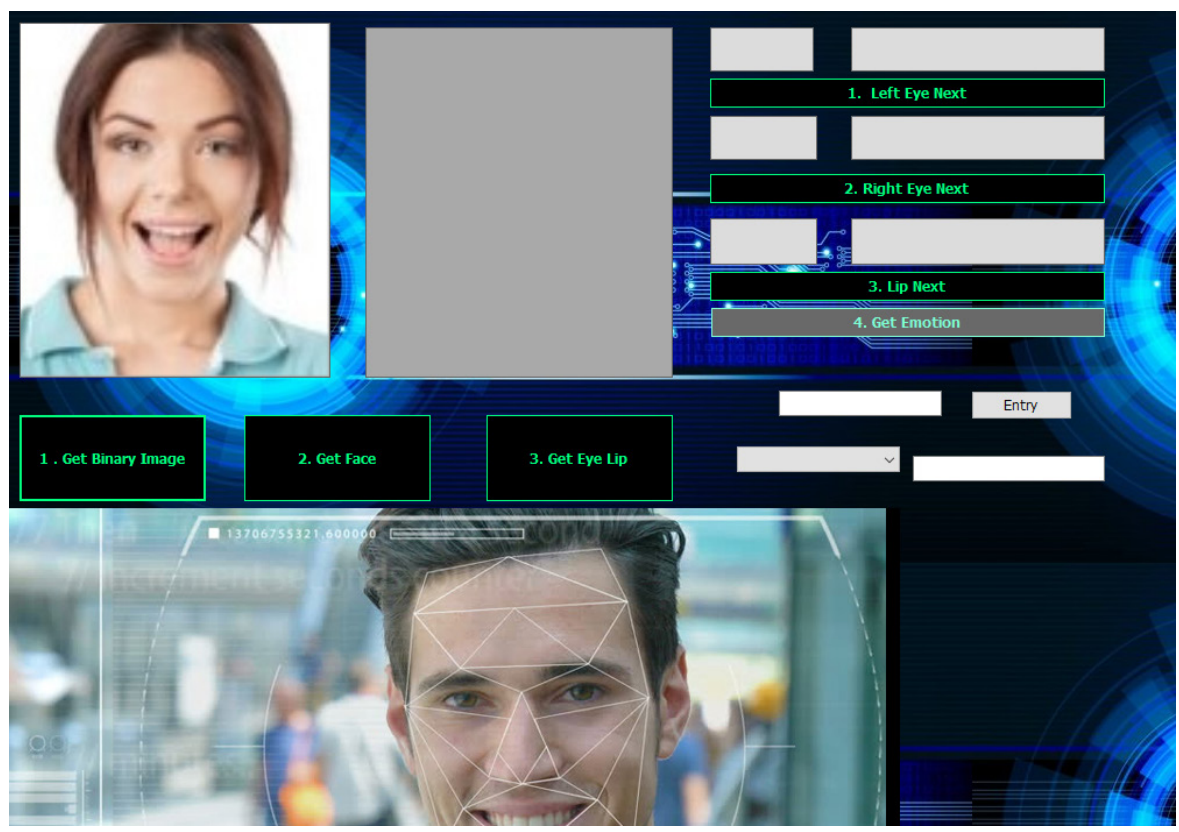

Figure 3: Inserted image from database.

Muhammd Muzammul, M. Awais and M. Yahya Saeed Education System re-engineering with Al (artificial intelligence) for Quality Improvements with proposed model
ADCAIJ: Advances in Distributed Computing and Artificial Intelligence Journal Regular Issue, Vol. 8 N. 2 (2019), 51-60 elSSN: 2255-2863 - http://adcaij.usal.es Ediciones Universidad de Salamanca - CC BY NC DC 
Step2

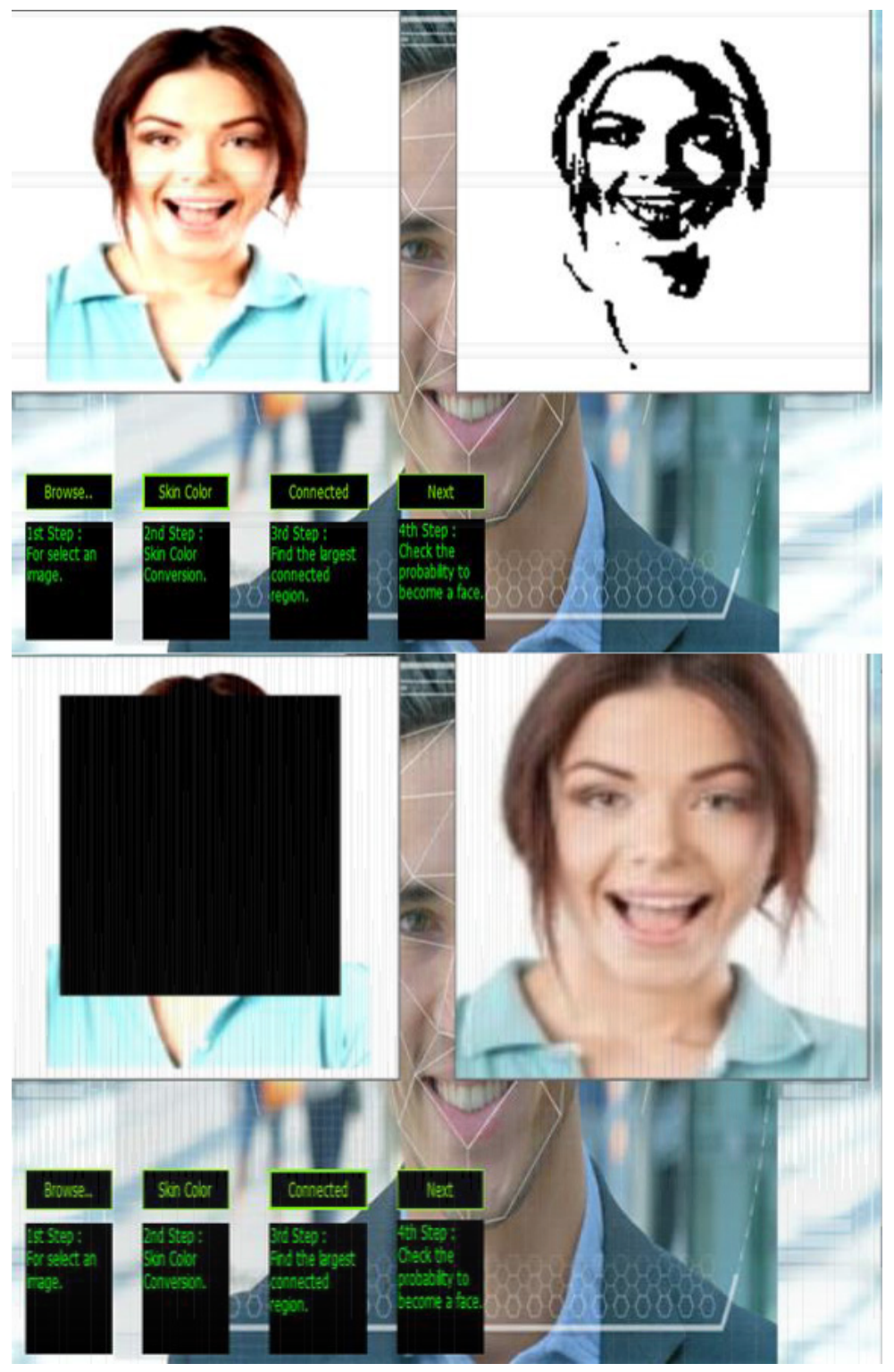

Fiigure 4: Skin color conversion and getting desired area. 


\section{Step3:}

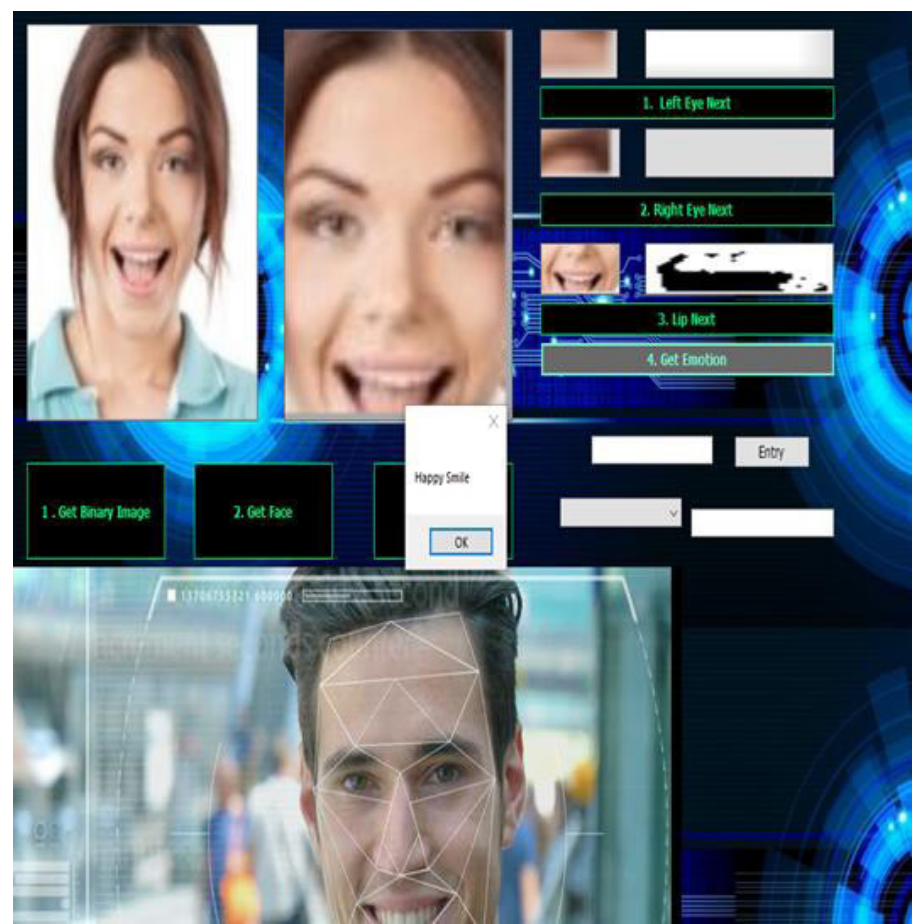

Figure 5: Getting eye, lips, emotions (representing implementation on single image).

\section{Conclusion}

This paper worked on a model-based approach, the focus was to implement the artificial application in the educational field. The educational improvements can bring a change in any society. We implemented whole research on Fatima Jinnah educational institute. It is locate in Jhang region, Pakistan and working with over 50 branches all over the country.

We implemented a face recognition based attendance system with the use of 2D DWT-, Principal component analysis (PCA) and K-nearest neighbor classification. Students attendance improved from $50 \%$ to $90 \%$ as the automated attendance system implemented in this education branch. After recognition captured images used for the facial expression recognition system (FERS).Student behaviors monitored accordance recognized images after mid time of lecture passed. The system checks the emotions accordance students' activity in class as happy, whispering, attentive etc. Student's behaviors monitored for a month and got $90 \%$ improvements as they were thinking as someone monitors them. They can also introduce more educational activities as thumb recognition, in nearer future thum based attendance and face recognition based security can be great helpful for educational quality assurance.As we will adopt latest technology trends with artificial intelligence, we will be able to decrease security attacks in form of terorism. In previous decades educational institues were focused spot of terorists.

\section{References}

[1] M. Turk and A. Pentland, -Face recognition using eigenfaces,Proceedings. 1991 IEEE Comput. Soc. Conf. Comput. Vis. Pattern Recognit., pp. 586-591, 1991.

Muhammd Muzammul, M. Awais and M.Yahya Saeed Education System re-engineering with Al (artificial intelligence) for Quality Improvements with proposed model
ADCAIJ: Advances in Distributed Computing and Artificial Intelligence Journal Regular Issue, Vol. 8 N. 2 (2019), 51-60 eISSN: 2255-2863 - http://adcaij.usal.es Ediciones Universidad de Salamanca - CC BY NC DC 
[2] Visar Shehu, Agni Dika, "Using Real Time Computer Vision Algorithms in Automatic Attendance Management Systems" ITI 2010 32nd Int. Conf. on Information Technology Interfaces, June 21-24, 2010, Cavtat, Croatia.

[3] M. K. Rao, K. V. Swamy, and K. A. Sheela, -Face recognition using DWT and eigenvectors, 2012 1st Int. Conf. Emerg. Technol. Trends Electron. Commun. Netw., pp. 1-4, Dec. 2012.

[4] Y. Mao, H. Li, and Z. Yin, -Who missed the class? - Unifying multiface detection, tracking and recognition in videos, in 2014 IEEE International Conference on Multimedia and Expo (ICME), 2014, pp. 1- 6.

[5] Y. Xu, Q. Zhu, Y. Chen, and J. S. Pan, -An improvement to the nearest neighbor classifier and face recognition experiments,Int. J. Innov. Comput. Inf. Control, vol. 9, no. 2, pp. 543-554, 2013.

[6] D. Mateos-García, J. García-Gutiérrez, and J. C. Riquelme-Santos, -On the Evolutionary Weighting of Neighbours and Features in the k-Nearest Neighbour Rule,\|l Neurocomputing, 2017.

[7] M. Otair, -A Proximate K-Nearest Neighbour Based Spatial Clustering Using Kd-Tree,\| Int. J. Data- base Manag. Syst., vol. 5, no. 1, pp. 97-108, 2013.

[8] M. Turk and A. Pentland, -Eigenfaces for recognition,॥ J. Cogn. Neurosci., vol. 3, no. 1, pp. 71-86, Jan. 1991

[9] U. Jayaraman, S. Prakash, and P. Gupta, -An efficient technique for indexing multimodal biometric databases Umarani Jayaraman *, Surya Prakash and Phalguni Gupta,l Int. J. Biometrics, vol. 1, no. 4, pp. 418-441, 2009.

[10] Y. F. Li, M. Xie, and T. N. Goh, -A study of project selection and feature weighting for analogy based software cost estimation,\| J. Syst. Softw., vol. 82, no. 2, pp. 241-252, 2009.

[11] L. Hu and S. Nooshabadi, -Massive parallelization of approximate nearest neighbor search on KD- tree for high-dimensional image descriptor matching, $\|$ J. Vis. Commun. Image Represent., vol. 44, pp. 106-115, 2017.

[12] L. Li, T. Losser, C. Yorke, and R. Piltner, -Fast inverse distance weighting-based spatiotemporal interpolation: A web-based application of interpolating daily fine particulate matter $\mathrm{PM}<\inf >2: 5</$ inf $>$ in the contiguous U.S. using parallel programming and k-d tree,\| Int. J. Environ. Res. Public Health, vol. 11, no. 9, pp. 9101-9141, 2014.

[13] Z. Huang, W. Li, J. Shang, J. Wang, and T. Zhang, -Non-uniform patch based face recognition via 2D-DWT, IMAVIS, vol. 37, pp. 12-19, 2015.

[14] M. Turk and A. Pentland, -Eigenfaces for recognition,॥ J. Cogn. Neurosci., vol. 3, no. 1, pp. 71-86, Jan. 1991.

[15] Y. F. Li, M. Xie, and T. N. Goh, -A study of project selection and feature weighting for analogy based software cost estimation,\|l J. Syst. Softw., vol. 82, no. 2, pp. 241-252, 2009.

[16] Hanan Samet, The Design and Analysis of Spatial Data Structures. Addison - Wesley Publishing Company, Inc., 1990.

Muhammd Muzammul, M. Awais and M. Yahya Saeed Education System re-engineering with Al (artificial intelligence) for Quality Improvements with proposed model
ADCAIJ: Advances in Distributed Computing and Artificial Intelligence Journal Regular Issue, Vol. 8 N. 2 (2019), 51-60 eISSN: 2255-2863 - http://adcaij.usal.es Ediciones Universidad de Salamanca - CC BY NC DC 